\title{
Non-Linearity Behaviour of the ALBI Index: A Case of Johannesburg Stock Exchange in South Africa
}

\author{
Priviledge Cheteni
}

\author{
University of Fort Hare \\ Email:200909553@ufh.ac.za
}

Doi:10.5901/mjss.2014.v5n9p183

\begin{abstract}
Since the global financial crisis that crippled the world's financial markets in 2007, interest in nonlinear dynamics in form of deterministic chaos has increased. Hence, the main purpose of this study is to detect if whether stock returns exhibit nonlinear and chaotic tendencies. By using recent statistical tools to overcome some of the limitations faced in financial data. This study aims to detect low deterministic chaos in the Johannesburg Stock Market in South Africa. Using the powerful BDS test, LM test and Variance Ratio Test, the empirical results suggest that the ALBI index exhibit nonlinear tendencies and chaotic behaviour.
\end{abstract}

Keyword: Non-Linear, JSE, ALBI index, BDS, South Africa

\section{Introduction}

A number of econometric models have become insufficient to capture the nature of stock markets behaviour. In finance, it is very difficult to capture the chaotic and nonlinear behaviour of markets using econometric models, for instance, in markets were traders are always exposed to risks, speculation and volatility. Of late, nonlinear dynamics have become a critical part of research in a number of fields from econometrics, physics, mathematics, and economics. Previous research (Brooks \& Hinich, 1998; Lim \& Hinich, 2005; Espinosa, 2010) in the last decade has been reporting evidence of nonlinear behaviour in time series financial assets worldwide. Nonetheless, the current global financial crisis that was instigated by the United States subprime mortgage in 2007 has brought other features of the capital markets under scrutiny, because it is through these periods that inflows and outflows of speculative capitals show variability (Calvo, 2006). The Johannesburg Stock Exchange (JSE) ASSA Vanilla index is known as the ALBI index that contains the top twenty vanilla bonds. The ALBI index contains the top ten government bonds issued by the department of finance and they are fundamental different to any bonds in the market (JSE, 2013). The All Bond Index (ALBI) is composed of the most liquid sovereign and non-sovereign, for instance, local government, public utilities, and corporate bonds Therefore, high variability in the capital or stock markets could destabilise the local currency leading to serious disturbances in the economy. The evidence of nonlinear behaviour of the ALBI index may provide us with information on whether this period of volatility is permanent or temporary. This is necessary in enabling the government to make structural long-term decisions that would avoid the entrance of speculative inflows or short-term decisions that may lead to interventions on the exchange rates.

The majority of research has relied on linear modelling in trying to detect linearity in time series. Therefore, using a methodology designed to detect nonlinearity deterministic patterns in a time series, this study aims to broaden or add into the limited literature on previous research on the topic. The JSE Albi index is used to examine if the time series generates some form of chaos or non-linearity. In this regard, indexes exhibiting low deterministic chaos may contain vital information on inefficiencies, hence, it may help in predicting future stock returns.

\section{Literature Review}

A number of studies examining chaotic movements in stock markets have resurfaced in the past years. Mendez-Mercado and Willey (1992) recorded evidence of chaotic movement in the Japanese Nikkei Index, although later on failed to identify any chaotic process in the Dow Jones Industrial average and the Financial Times of London Industrial Index. Sewell, et al, (1993) recorded evidence of linear dependencies in the stock markets of Japan, Korea, and Hong Kong. Yet, Errunza, et al., (1994) noted nonlinear dependencies in the stock markets of Japan, Germany, Brazil, Chile, Mexico, and India. Although, evidence on non-linearity has been recorded in literature, it has been inconclusive. Scheinkman and 
LeBaron (1989) estimated the U.S stock returns index and found no evidence of linear dependence. In contrast, the same authors found evidence of linear dependence in the University of Chicago index. The conclusion was that, variations in weekly returns come from non-linearity as opposed to randomness. Similarly, Lim and Hinich (2005) tested fourteen stock indices from Asian countries and found nonlinearity, thus, concluded that the behaviour of indices is essential in financial time series irrespective of location. Bonilla, et al., (2008) tested the Embi index for non-linearity and found evidence that it exhibits chaotic tendencies.

Nonlinear deterministic process or models show the economy as dynamic process that is self-generating. Yet, in time series model the economy is seen as in equilibrium even though it is constantly affected by external shocks. Therefore, nonlinear models reveal a lot of information such as stock markets crash and large movements that are not easily explained by linear models. Financial data is generally faced with limitations of sample size and non-stationarity. In order to overcome these limitations, this study utilizes recent statistical methodologies to identify low dimensional deterministic chaos in one of the major stock exchange in Africa. By so doing, it fills the important gap in the existing literature.

\section{Data and Methodology}

For empirical analysis, we use the ALBI Index at daily frequency (7 days a week). The sample includes 3912 observations for the period of $1^{\text {st }}$ January 2003 to 17 September 2013. The Johannesburg Stock Exchange provided the data. The use of the BDS Test (Brock, et al.,1987) and Engle LM Test is very common in studying non-linearity. The BDS test is a portmanteau test statistic that can be used to detect non-linearity dependencies of a series. Hence, the null hypothesis states that the series are independently and identically distributed. The BDS test was previously applied by (Liu, et al., 1992; Kanzler, 1998; Panagiotidis, 2005; Winker and Jeleskovic, 2007). The LM test detects disturbances in $\mathrm{ARCH}$ residuals. EViews version 8 was used to analyse data in the study.

Table 1 presents descriptive statistics for the series under study. These are; standard deviation, skewness, kurtosis, and the Jarque- Bera test for normality. Skewness and Kurtosis values were less than one and three respectively suggesting that the distribution was not normal. Moreover, the Jaque-Bera statistic was significant at less than $0.05 \mathrm{p}$-values suggesting that the distribution was not normal.

Table 1: Descriptive statistics

\begin{tabular}{|c|c|c|c|c|c|c|c|c|}
\hline Mean & Median & Max & Min & Std. Dev. & Skewness & Kurtosis & Jarque-Bera & Obs \\
\hline $\mathbf{2 8 1 . 1}$ & 257.4 & 461.2 & 155.8 & 79.2 & 0.47 & 2.22 & $245.7^{\star \star \star}$ & 3913 \\
\hline
\end{tabular}

*** indicate significance level at 5 percent level.

\subsection{BDS Test}

A BDS test uses a concept of spatial correlation in chaos theory. Chaos theory is based on assumption that the underlying time series system is non-linear and deterministic. BDS test is powerful in detecting serial dependence in time series by testing the null hypothesis of independent and identically distributed (I.I.D) against unspecified alternative. The BDS tests non-linearity given that any linear dependence has been removed from the data by taking out the first difference of natural logarithms. For the full steps on the BDS test, see Brock, Dechert, Scheinkman, and LeBaron (1996). The computations of the BDS are as follows:

If a time series has $\mathrm{N}$ observations that should be differenced of natural logarithms of raw data in time series

$\left\{\chi_{i}\right\}=\left[\chi_{1}, \chi_{2}, \chi_{3}, \ldots \ldots . \chi_{N}\right]$

Select a value of $\boldsymbol{m}$ (embedding dimension and embed the time series into $\boldsymbol{m}$ dimensional vectors by taking $\boldsymbol{m}$ successive points in the series. This converts the series of scalars into series of vectors with overlapping entries

$\left\{\chi_{1}^{m}\right\}=\left[\chi_{1}, \chi_{2}, \chi_{3}, \ldots \ldots . \chi_{m}\right]$

$\left\{\chi_{2}^{m}\right\}=\left[\chi_{2}, \chi_{3}, \chi_{4}, \ldots \ldots . \chi_{m+1}\right]$

$\left\{\chi_{N-m}^{m}\right\}=\left[\chi_{N-m,} \chi_{N-m+1}, \ldots \ldots \ldots \chi_{N}\right]$

Compute the correlation integral with the dimension $\boldsymbol{m}$ and distance $\epsilon$ as follows:

$C_{m}(d)=\frac{1}{n_{m}\left(n_{m}-1\right)} \sum_{i \neq j} \mathrm{I}\left(\chi_{p}^{n}, \chi_{p}^{n}\right)$

Where $n_{m}=n \cdot m+1$ and $\mathrm{I}\left(\chi_{p}^{n}, \chi_{p}^{n}\right)=1$ if the maximal norm $\left\|\chi_{p}^{n}, \chi_{p}^{n}\right\|<$ distance $\epsilon$ and 0 otherwise. 
Therefore, the BDS test values can be obtained using this formula:

$$
B D S_{\epsilon, m}=\frac{\sqrt{n}\left[c_{m}(\epsilon)-C_{1}(\epsilon)^{m}\right]}{\sqrt{V_{\epsilon, m}}} . .
$$

Where $\sqrt{V_{\epsilon, m}}$ is a standard deviation in equation (4). If $B D S_{\epsilon, m}>2$ the null hypothesis is rejected with a confidence level of 95 percent, and if $B D S_{\epsilon, m}>3$ the null hypothesis is rejected at 99 percent confidence interval. The correlation integral is a measure of proportion that any pairs of $\boldsymbol{m}$-vectors $\left(\chi_{p}^{n}, \chi_{p}^{n}\right)$ are within distance $\epsilon$. The BDS test is dependent on $\boldsymbol{m}$ and $\epsilon$. Hence, no criterion to determine these two parameters. Rothman (1992) notes that the BDS test has a lower power against certain forms of non-linearity such as self-exciting threshold AR processes. Therefore, it can be concluded that it is robust to random variables that do not possess high order moments.

\subsection{The Engle LM test}

In 1982 Engle made a ground breaking discovery by suggesting that the LM test can detect ARCH disturbances since it is a Lagrange Multiplier test. The test is based on the $\mathrm{R}$ squared of an auxilliary regression. It is defined as follows

$$
e_{t}=\beta_{0}+\sum_{k=1}^{p} \alpha \beta_{k} e_{t-k}^{2}+\varepsilon_{t}
$$

The LM test is computed on auxiliary regression to test the null hypothesis that there is no ARCH up to order $p$ in the residuals. Where $e$ is the residual. Equation 5 is a regression of the squared residuals on a constant and lagged squared residual of up to order $p$. The LM test is asymptotically distributed as a $\chi^{2}(p)$ under quite conditions.

\subsection{Variance Ratio Tests}

The Lo and MacKinlay $(1988,1989)$ overlapping variance tests, compares the variance of differences in returns calculated over intervals by examining the predictability of the time series. If the returns are assumed to follow a random walk, the variance of $q$ - period difference should be $q$-times the variance on a single period. The tests are as follows:

$$
\begin{aligned}
& \left(Y_{t}\right)=\left(Y_{0}, Y_{1}, Y_{2}, \ldots \ldots ., Y_{T}\right) . \\
& \Delta Y_{t}=\mu+\epsilon_{t} \ldots \ldots \ldots \ldots \ldots \ldots \ldots . .
\end{aligned}
$$

Where $\mu$ is a drift parameter and $E\left(\epsilon_{t}\right)=0$ for all $t$, and $E\left(\epsilon_{t} \epsilon_{t-j}\right)=0$ for any positive $j$. Lo and Mackinlay make the strong assumption that the $\epsilon_{t}$ are I.I.D Gaussian with a variance $\delta^{2}$ (the normality assumption is not strictly). Following Kim (2006), the test can be used to bootstrap and improve the sample properties of variance ratio tests. This process can be computed by using the individual Lo and Mackinlay, and joint (Chow et al., 1993) variance ratio statistics on samples of T observation by weighting the original data by mean 0 and variance 1 random variables. In this study, the test is computed by allowing heteroscedasticity in the data and using bootstrapping to evaluate the statistical significance. The Wild bootstrap in a two-point distribution is set at 5000 replications, using the Knuth generator and a seed of the random number generator of 1000 .

\section{Results and Analysis}

The JSE is characterised by deep structural, functional, and institutional dysfunctions like any other emerging capital/stock market. Birau (2011) notes that emerging stock markets are faced with high volatility, existence of bubbles, panic , speculation, high risk investments, low level of liquidity, reduced capitalisation, reduced number of transactions, insufficient development of financial instruments, exchange rate instability, and many other challenges. A chaotic behaviour can be seen in Figure 1 especially after the 2007 global financial crisis were the index has been ever increasing.

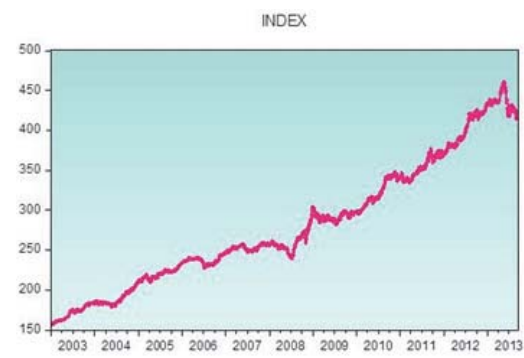

Figure 1. The ALBI Index performance for the period of 2003 to 2013 
Similarly Figure 2 shows the daily returns for the JSE ALBI index for a period of 10 years. The daily returns have been hovering around the mean zero, hence, this suggests that there are periods of high volatility were days of large movements are followed by days with the same features, especially from year 2007 going forward. High volatility clustering entails a strong autocorrelation or $\mathrm{ARCH}$ effect in the squared returns.

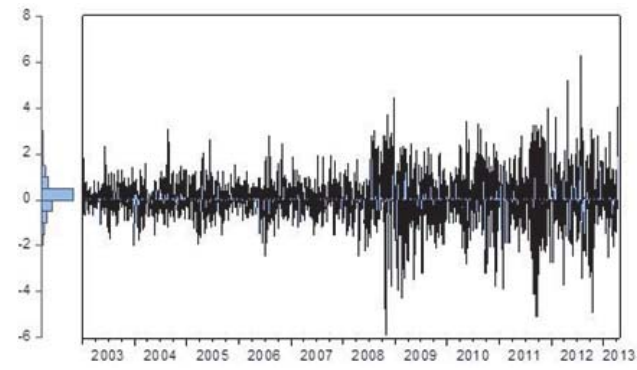

Figure 2: Daily returns for the JSE ALBI index during the period of 01 January 2003 to 17 September 2013

\subsection{LM Test results}

The results in Table 2 reveal that there is evidence of ARCH effects in time series as the $p$-value is less that 0.05 percent level. Therefore, we strong reject the null hypothesis that the Albi index is I.I.D and conclude that the returns are nonlinear and dependent.

Table 2. LM Test results

\begin{tabular}{|c|c|c|}
\hline Engle Test & Prob & F-Statistic \\
\hline Using up to lag 1 & $0.0027^{\star \star \star}$ & 9.019370 \\
\hline Using up to lag 2 & $0.0020 * \star \star$ & 6.238643 \\
\hline Using up to lag 3 & $0.0054^{\star \star \star}$ & 4.2312233 \\
\hline Using up to lag 4 & $0.0001^{\star \star \star}$ & 5.686631 \\
\hline
\end{tabular}

\subsection{BDS test results}

A non-linearity test on time series was done using a BDS test. A dimension $m$ from 2-6 and distance $(\epsilon)$ of 0.7 were selected to complete the test. The null hypothesis was that the time series data is independently and identically distributed (I.I.D) and the alternative hypothesis was stating that the time series is non-linearly or non I.I.D. The test indicates that all $p$ - values of the BDS test statistics are less than the 5 percent significant level. Thus, we should strongly reject the null hypothesis of I.I.D. The results presented in Table 3 clearly suggests that the time series is non-linearly dependent, hence, showing indications of chaotic behaviour. A lower $\epsilon$ value represents a stringent criteria since the $\mathrm{m}$ dimensional space must be clustered close together in terms of the BDS statistics. Hence, $\epsilon=0.7$ represents a stringent approach, and $\mathrm{m}=6$ as the highest dimension. A higher dimensional would severe limit the confidence in the BDS statistics and the interest of the study is to identify low dimensional deterministic chaos.

Table 3. BDS tests bootstrap results

\begin{tabular}{ccccccc}
\hline Dimension & Distance $(\boldsymbol{\epsilon})$ & BDS Statistic & Std. Error & z-Statistic & Normal Prob. & Bootstrap Prob. \\
2 & 0.7 & 0.028824 & 0.001973 & 14.60734 & $0.0000^{\star \star \star}$ & $0.0000^{\star \star \star}$ \\
3 & 0.7 & 0.045856 & 0.003144 & 14.58696 & $0.0000^{\star \star \star}$ & $0.0000^{\star \star \star}$ \\
4 & 0.7 & 0.056852 & 0.003755 & 15.14056 & $0.0000^{\star \star \star}$ & $0.0000^{\star \star \star}$ \\
5 & 0.7 & 0.062517 & 0.003927 & 15.92019 & $0.0000^{\star \star \star}$ & $0.0000^{\star \star \star}$ \\
6 & 0.7 & 0.065212 & 0.003801 & 17.15804 & $0.0000^{\star \star \star}$ & $0.0000^{\star \star \star}$ \\
\hline
\end{tabular}

\footnotetext{
*** represents $p$-value at 0.05 percent level
} 
The results above suggest that after removing linear correlations, the ALBI index returns exhibit randomness, even in a six dimensional space. The bootstrap probabilities are significantly at 0.05 percent level. The results were simulated with 1000 repetitions following Brock et al., (1987). Therefore, the null hypothesis of I.I.D is strongly rejected. It should be noted that the rejection of I.I.D can be influenced by regulatory reforms or regime change among other factors giving returns an appearance of non-randomness (although the returns maybe random is stable periods).

\subsection{Variance Ratio test results}

According to Table 4, the individual tests for the period 2,5,10,20 and 30 years were statistical significant at 0.05 level. The $p$-values of the individual variance ratio tests were all generated using the wild bootstrap. The individual test statistic strongly rejects the null hypothesis of independent and identically distributed (I.I.D). The Chow-Denning joint test statistic of 3.453 has a bootstrap value of 0.0012 and strongly rejects the null hypothesis that the log of Index is a martingale or I.I.D.

Table 4: Variance Ratio test results

\begin{tabular}{|c|c|c|c|c|}
\hline \multicolumn{2}{|c|}{ Joint Tests } & Value & df & Probability \\
\hline \multicolumn{2}{|c|}{$\operatorname{Max}|z|$ (at period 2) } & 3.453202 & 3912 & $0.0012^{\star \star \star}$ \\
\hline \multicolumn{5}{|c|}{ Individual Tests } \\
\hline Period & Var. Ratio & Std. Error & z-Statistic & Probability \\
\hline 2 & 1.074870 & 0.021681 & 3.453202 & $0.0000^{\star \star \star}$ \\
\hline 5 & 1.144031 & 0.045679 & 3.153110 & $0.0004^{* \star *}$ \\
\hline 10 & 1.144043 & 0.069420 & 2.074960 & $0.0384^{\star * *}$ \\
\hline 20 & 1.205971 & 0.102983 & 2.000056 & $0.0412^{\star \star \star}$ \\
\hline 30 & 1.263782 & 0.127071 & 2.075866 & $0.0302^{\star \star \star}$ \\
\hline
\end{tabular}

\section{Conclusions}

The purpose of this study was to examine the possibility that the time series of the JSE ALBI index exhibit nonlinear structure and low deterministic chaos. The study used the daily returns of the ALBI index covering the January 2003 to September 2013 period.

The study utilized the BDS test, Engel LM test and the Variance ratio test to detect nonlinear dependence in the stock returns. Analyses from all the nonlinear and linear tests reveal that the ALBI index indicates the existence of nonlinearity in raw and filtered returns. Furthermore, the findings point to a strong dependence in the stock returns and chaotic behaviour. The results are similar to Pandey, et al., (1997) and Urrutia, (1995) who noted that stock returns exhibit non-linearity and chaotic tendencies. Interdependence in stock returns means that prices of stocks can be predicted using past data.

The following are the contributions of this study to literature on stock returns: the study utilized a number of tests to detect non-linearity and chaos to stock returns; further the study found amply evidence that the ALBI index exhibits nonlinearity and dependence tendencies coupled with chaos behaviour. The findings from the study have a serious implication to financial market forecasting in that, it can be noted that emerging markets such as the Johannesburg Stock Exchange cannot be simply explained by the use of equilibrium models, such as, the efficient market hypothesis. Nonlinear theories or models aim to go beyond efficiency in markets by explaining the dynamic, unpredictable, nonlinear systems in the financial markets.

\section{References}

Birau, F., 2011. The implications of chaos theory on Bucharest Stock Exchange. Craiova,Romania: University of Craiova.

Bonilla, C., Maquieira, C. \& Romero-Meza, R., 2008. Nonlinear behavior of emerging markets bonds spreads: the Latin American Case. Applied Economics, 40(20), pp.2997-702.

Brock, W., Dechert, W. \& Scheinkman, J., 1987. A test for independence based on the correlation dimension. Working Paper. University of Wisconsin-Madison.

Brock, W., Dechert, W., Scheinkman, J. \& LeBaron, B., 1996. A test for independence based on the correlation dimension. Econometric Reviews, 15, pp.197-235. 
Brooks, W. \& Hinich, M., 1998. Testing non linearity in the daily sterling exchanges rates. Applied Financial Economics, 6, pp.307-17.

Calvo, G., 2006. Monetary policy challenges in Emerging Markets: Sudden stop, Liability Dollarization and lender of last resort. Working Paper. Inter-American Development Bank.

Chow, K., V \& Denning, K., 1993. A simple multiple variance ratio test. Journal of Econometrics, 58, pp.385-401.

Errunza, V., Hogan, J., Kini, O. \& Padmanabhan, P., 1994. Conditional heteroscedasticity and global stock return distributions. Financial Review, 29, pp.293-317.

Espinosa, C., 2010. Chaos in the commodities market. Revista Cuadernos de Economia Colombia, 29(53), pp.155-77.

JSE, 2013. Johannesburg Stock Exchange. [Online] Available at: www.jse.co.za [Accessed 23 November 2013].

Kanzler, L., 1998. A study of the efficiency of the foreign exchange market through analyses of ultra-high frequency data. Dissertation. University of Oxford.

Kim, J., 2006. Wild bootstrapping variance ratio tests. Elsevier, 92(1), pp.38-43.

Lim, K. \& Hinich, M., 2005. Cross temporary universality of non linear serial dependencies in Asian stock markets. Economics Bulletin, 7 , pp.1-6.

Lim, K. \& Hinich, M., 2005. Cross-Temporal universality of non-linear seril dependencies in Asian Stock Markets. Economics Bulletin, 7(1), pp.1-6.

Liu, T., Granger, W. \& Heller, W., 1992. Using the correlation exponent to decide whether an economic series is chaotic. Journal of the American Statistical Association, 7, pp.25-39.

Lo, A. \& Mackinlay, A., 1988. Stock market prices do not follow random walks: Evidence from simple specification Test. Review of Financial Studies, 38, pp.41-66.

Mendez-Mercado, J. \& Willey, T., 1992. Testing for nonlinear dynamics in international stock indices. Working Paper. Central Missouri State University.

Panagiotidis, T., 2005. Market capitalization and efficiency.Does it matter? Evidence from Athens Stock Exchange. Applied Financial Economics, 15, pp.707-13.

Pandey, V., Kohers, T. \& Kohers, G., 1998. Deterministic nonlinearity in the stock returns of major European equity markets and the United States. The Financial Review, 33, pp.45-64.

Scheikman, J. \& LeBaron, B., 1989. Nonlinear Dynamics and Stock Returns. Journal of Business, 62, pp.311-37.

Sewell, S., Stansell, S., Lee, L. \& Pan, M., 1993. Nonlinearities in emerging foreign capital markets. Journal id Business finance and accounting, 20, pp.237-48.

Urrutia, J., 1995. Tests of random walk and market effciency for Latin American emerging markets. Journal of Financial Research, 18(3), pp.299-309.

Winker, P. \& Jeleskovic, V., 2007. Dependence of and long memory in Exchange Rate Returns: Statistics, Robustness, Time aggregation. Working paper. University of Essex. 